\title{
FALHAS REPRODUTIVAS EM VACAS LEITEIRAS
}

Vitor Lemes Silva, Flávio Henrique de Paula, Aline Sousa Camargos, Jeferson Corrêa Ribeiro, Andreia Santos Cezário, Wallacy Barbacena Rosa Dos Santos

Departamento de Zootecnia, Instituto Federal de Educação, Ciência e Tecnologia Goiano Campus Morrinhos, Morrinhos, GO. E-mail: vitorlemes18@hotmail.com

\section{RESUMO}

Conhecer as principais causas que influenciam o índice reprodutivo de um rebanho ajuda a entender como elas agem e a melhor maneira para controlá-las, e aumentar os ganhos com a bovinocultura, que a cada ano que passa se especializa para poder continuar em alta no mercado. Um bom programa de manejo sanitário, aliado a um controle eficiente dos dados de cada animal, é de grande importância para o sucesso do controle das falhas reprodutivas. Este artigo teve por objetivo revisar as falhas reprodutivas mais frequentes de vacas leiteiras em fazendas de alta produção.

Palavras-chave: fazendas; aborto; natimorto

\section{REPRODUCTIVE FAILURES IN DAIRY COWS}

\begin{abstract}
Knowing the main causes that influence the reproductive index of a herd helps to understand how they act and the best way to control them, and to increase the gains with the bovine production, that every year that passes specializes to be able to continue in the market high. A good sanitary management program, coupled with an efficient control of the data of each animal, is of great importance for the success of the control of reproductive failures. This article aimed to review the most frequent reproductive failures of dairy cows on high yield farms.
\end{abstract}

Keywords: farms; abortion; stillbirth

\section{INTRODUÇÃO}

O setor leiteiro tem sofrido uma grande evolução, graças ao desenvolvimento de novas técnicas e procedimentos intensivos, as explorações leiteiras dos países mais desenvolvidos, aumentaram de forma significativa o número de vacas em lactação por exploração, assim como a produtividade individual, o que proporcionou o aumento da produção e da rentabilidade. Sucesso esse ocasionado pela rigorosa seleção genética dos melhores animais, associado ao ajustamento da nutrição, buscando o melhor alimento utilizado nas dietas e o manejo de maneira geral (Lopes, 2013).

A eficiência reprodutiva do rebanho destaca-se como um dos principais aspectos responsáveis pelo desempenho econômico da atividade, um fator determinante para a continuação do homem no campo (Oliveira et al., 2006).

Existem várias barreiras para o aprimoramento da eficiência reprodutiva em uma propriedade leiteira, como por exemplo, as perdas reprodutivas decorrentes de causas infecciosas, ou mau manejo, falhas que podem causar danos desde a concepção até o momento do parto. Nos bovinos de maneira geral, a mortalidade pré-natal, morte embrionária e fetal, são consideradas as maiores causas de falhas no que diz respeito à reprodução (Camargos, 2009; 
Paula, 2015). A maior incidência de perdas pode ou não ser provocada por um agente infeccioso, no decorrer dos 35 primeiros dias de gestação, acometendo até $40 \%$ dos conceptos, tais perdas incidem no sucesso da reprodução, diminuindo a rentabilidade da atividade (Bergamaschi et al., 2010; Silva et al., 2014).

Khodakaram-Tafi \& Ikede (2005) e, Mcewan \& Carman (2005), relacionam com as perdas reprodutivas cerca de 37 a $50 \%$ de perdas na gestação com as doenças infecciosas, números esses que em qualquer dimensão de propriedade são assustadores. Um exemplo seria um sítio com 20 animais no rebanho e $50 \%$ de mortes na gestação, o que representaria menos de dez animais em um intervalo de um ano.

Os estudos mostram a importância dos sistemas de produção e a influência que esses trazem para o aumento da produtividade. Ressaltando a importância do manejo, no que diz respeito ao controle zootécnico no intuito de controlar as principais enfermidades que acometem os bovinos, pela ampla dimensão que essas tomam dentro de um rebanho, e a influência direta que se faz na rentabilidade da atividade. Conhecer e quantificar as falhas reprodutivas e sua influência direta na produção do rebanho como um todo, ajuda a se preparar e criar de maneira mais eficaz, através do conhecimento das principais causas de infertilidade e perdas gestacionais que acometem os bovinos, um modelo de controle zootécnico que permita avaliar de maneira mais segura, no que se refere ao manejo sanitário, nutricional e de criação que reduza as taxas de descarte e perdas no rebanho.

O desempenho reprodutivo não é apenas fazer um bom ciclo de monta, ou uma inseminação bem feita, mas sim a gestação ir a termo e o bezerro chegar a nascer. Estudos têm mostrado altas taxas de fertilização das vacas variando de 80 a 100\% em manejos especializados. Passados 30 dias, a taxa de concepção cai para 28 a 40\%, demostrando as falhas reprodutivas que resultam em perdas, pelas mais variadas causas, como erros de manejo e doenças multifatoriais (Pereira, 2012).

Várias são as enfermidades reprodutivas que acometem os bovinos. Dentre as falhas mais comuns, pode-se destacar além do aborto, o anestro, a gestação gemelar e a natimortalidade. Estas podem ser causadas por doenças da reprodução, interferindo nos índices reprodutivos, como taxa de natalidade, taxa de prenhez, retorno ao cio, e morte do feto (Juffo, 2010). Ocorrendo o aumento do descarte involuntário dos animais por mastite, problemas de casco, abortos, ocorrência contínua de natimortos, dificuldade para emprenhar, influenciando na diminuição da longevidade, o número de animais para reposição, menor progresso genético, maior gasto com inseminação e com medicamentos. Além disso, há redução na produção de leite (Carneiro et al., 2010).

Conhecer as principais causas que influenciam o índice reprodutivo de um rebanho ajuda a entender como elas agem e a melhor maneira para controlá-las, e aumentar os ganhos com a bovinocultura, que a cada ano que passa se especializa para poder continuar em alta no mercado. Um bom programa de manejo sanitário, aliado a um controle eficiente dos dados de cada animal, é de grande importância para o sucesso do controle das falhas reprodutivas (Camargos, 2013).

Este artigo teve por objetivo revisar as falhas reprodutivas mais frequentes de vacas leiteiras em fazendas de alta produção.

\section{FALHAS REPRODUTIVAS}

Anestro

O anestro corresponde ao período de transição que as vacas passam entre o pós-parto e o retorno ao cio. Vacas taurinas apresentam menores números de intervalo de partos em relação às fêmeas zebuínas (Alves et al., 2002). Isto ocorre devido a diferenças fisiológicas como, por exemplo, o tempo de duração do cio. Nas zebuínas, dura em média 10 horas, com ocorrência de $50 \%$ da manifestação no período noturno, o que dificulta sua observação, sendo a possibilidade de 
$30 \%$ dos animais que iniciam a noite terminarem a noite. 0 estro tem duração de 12,9 horas em zebuínas e 16,3 horas nas taurinas (Mizuta, 2003).

Dentro do exposto, a questão do anestro pode ser um problema dentro da fazenda o que pode estar relacionado com o tipo de rebanho utilizado (Grohn \& Rajala-Schultz, 2000; Barbosa et al., 2011).

Vários fatores podem estar relacionados ao aumento do tempo referente ao anestro de vacas em lactação. O estado nutricional no período pré e pós-parto é um desses fatores (Echternkamp et al., 1982; Lalman et al., 1997).

Na maioria das vezes, este é um fator que dificulta a resposta aos tratamentos de indução de estro (Baruselli et al., 2004). O balanço energético negativo (BEN) é um dos responsáveis pela diminuição da fertilidade de uma fêmea devido à excessiva perda de peso após o parto, pela diminuição do consumo de matéria seca nesse período em conjunto com o baixo escore de condição corporal (Butler, 2000; 2003).

A nutrição tem um papel de suma importância na regulação das necessidades do animal tanto de mantença quanto produtivas. Um quadro de subnutrição ou de baixo consumo decorrentes no pós-parto se tornam fatores de prolongamento do anestro (Montiel \& Ahuja, 2005). É importante que essas vacas tenham uma boa quantidade de reservas energéticas, para não sofrer distúrbios metabólicos no pós-parto que venham a afetar tanto a produção quanto a saúde dos animais e sua vida reprodutiva (Montiel \& Ahuja, 2005).

Observa-se uma redução significativa na fertilidade de vacas, principalmente as de leite e com alta produção, devido ao conflito entre as necessidades de mantença e reprodutiva (Silva, 2015).

Dentre os principais fatores envolvidos na duração do anestro que acarretam perdas econômicas na atividade, pode-se citar, as deficiências nutricionais no período de transição do animal, a alta produção de leite das vacas (Thatcher et al., 2006; Silva, 2015), o estímulo da mamada provocado pelo bezerro no aleitamento e a ocorrência de balanço energético negativo no pós-parto (Pinheiro et al., 2013; Silva, 2015).

A seleção de vacas mais eficientes para produção de leite, também é um dos fatores responsáveis pela diminuição da eficiência reprodutiva, sendo caracterizada como uma das sequelas da seleção artificial (Bagnato \& Oltenacu, 1994).

Ruas et al., (2002) apontam que vacas mestiças têm atraso no retorno ao cio, permanecendo em anestro por mais tempo. Aumento do período de serviço e um prolongado intervalo de partos podem ser ocasionados pelo longo período de anestro, o que resulta na baixa eficiência reprodutiva do rebanho (Atanasov et al., 2012; Silva, 2015).

O intervalo de partos ideal é de 12 meses, considerando um bezerro por ano. Se o intervalo de partos é maior, afeta a produção do animal, resultando na diminuição do número de lactações, com consequente baixa na produção de leite da vida útil da vaca (Rabassa et al., 2007).

O número de parições interfere na duração do período de anestro das vacas, com maior incidência em primíparas do que multíparas (Yavas \& Walton, 2000), devido ao BEN ser mais acentuado em primíparas (Bellows et al., 1982), que além do baixo consumo e a alta produção, ainda tem que utilizar suas reservas de nutrientes para completar o seu desenvolvimento corporal.

Em rebanhos leiteiros bem manejados, a taxa de ovulação é de $90 \%$ das vacas até o 40 이 dia pós-parto. Nos rebanhos em que o sistema é de bezerro ao pé, esse índice cai para $60 \%$, devido ao efeito da amamentação sobre a retomada da atividade ovariana pós-parto (Alvarez, 2013).

Não são exatos os estudos em relação ao efeito da mamada ou a presença do bezerro ao pé nas criações de leite e corte. Sabe-se que restrições temporárias do contato mãe e filho, separação imediata após o parto ou desmame precoce podem aumentar a fertilidade das fêmeas. Isto impede os hormônios inibidores de GnRH e/ou LH de atuarem (Peter et al., 2009). Lamb et al. 
(1997) apontam que o intervalo do anestro pode ser menor em fêmeas que o vitelo é desmamado ou é impedido de ter contato com a mãe após 13 dias do parto.

Animais em produção de leite quando submetidos à temperatura ambiente e umidade do ar acima das indicadas para o conforto térmico, ou seja, em estresse térmico, apresentam redução na manifestação de cio, nas taxas de ovulação e prenhez (Hansen \& Arechiga, 1999; Lopez-Gatius et al., 2005; Barbosa et al., 2011).

\section{Aborto}

Denomina-se como aborto a expulsão do feto vivo ou morto do útero entre 42 dias até aproximadamente 280 dias de gestação, quando este é incapaz de exercer uma vida independente em um ambiente extrauterino (Juffo, 2010).

$\mathrm{O}$ aborto pode acontecer nas várias fases da gestação dos bovinos. $\mathrm{O}$ diagnóstico é feito através de exames do feto e da placenta e pode ser provocado por diversas doenças como: leptospirose, brucelose, neosporose, complexo herpes vírus, diarreia viral bovina, abortos micóticos.

As causas infecciosas de aborto podem ser separadas em quatro grupos, são eles: protozoários, bactérias, fungos e vírus. Em rebanhos leiteiros, devido ao sistema de criação e manejos adotados, é o que mais se preocupa, estuda e se tem dados em relação a diagnósticos com aborto pelas mais diversas causas (Juffo, 2010).

As principais doenças que acometem a reprodução dos bovinos no Brasil são a IBR, BVD e leptospirose, em maior quantidade. A brucelose também é uma das causas de grande preocupação. Estas doenças são responsáveis pelas falhas na ovulação, diminuição na qualidade dos oócitos, perdas embrionárias e fetais (Grooms et al., 2007; Kelling, 2007; Grooms, 2010; Aono, 2012).

A leptospirose é uma doença infectocontagiosa de distribuição mundial. De caráter zoonótico, causada por bactérias do gênero Leptospira, que acomete os animais domésticos como: bovinos, suínos, equinos, muares, gatos e cães, com relatos da ocorrência também em vários animais selvagens (Monteiro, 2011).

Por ser transmitida por roedores leptospirose é de extrema importância, devido muitas vezes a falta de higiene nas propriedades e ao mau armazenamento dos alimentos principalmente os grãos, se caracterizando como a fonte de contaminação mais comum. Dentre a profilaxia mais indicada para o controle da leptospirose, inclui-se adotar medidas importantes de controle de roedores, os quais são os maiores disseminadores do agente etiológico, a eliminação do excesso de água que fique parada ou represada no ambiente, isolamento e tratamento dos animais doentes, detecção e tratamento dos doentes e imunização sistemática dos animais (Silva et al., 2012).

Cortez et al. (2006) e Mineiro et al. (2007) consideram a leptospirose uma das causas responsáveis pelo baixo desempenho reprodutivo de bovinos com diagnóstico confirmado para tal doença. De caráter zoonótico acometendo bovinos nas diversas fases de vida, seus sinais clínicos manifestados na forma aguda, apresentam quadros de febre e mastite nas vacas, nos bezerros, além de febre, são decorrentes sinais de anorexia, hemoglobinúria, casos de encefalite, acessos convulsivos e alta mortalidade (Faine 1994; Burns et al., 2010; Aono, 2012).

Nos bovinos, a leptospirose ocasiona, principalmente, abortamentos, infertilidade, ocorrência de natimortos e retenção de placenta, sendo considerada uma das responsáveis pela baixa produtividade da pecuária nacional (Givens, 2006, Silva, 2015).

Os abortos geralmente são tardios, com mais de seis meses de gestação (Riet-Correa et al., 2007), sinal clínico também observado em casos de brucelose.

Segundo Antoniassi et al. (2007), a leptospirose é uma zoonose de incidência mundial e caracterizada como a principal causa de aborto por bactérias em bovinos. É causada mais 
frequentemente por Leptospira interrogans. Tem sua transmissão pelo contato direto com a urina, pele, mucosa oral e conjuntival de animais portadores das doenças (Aono, 2012).

A brucelose bovina representa uma enfermidade de caráter infeccioso, causada por bactérias do gênero Brucella, principalmente pela Brucella abortus, o hospedeiro principal é o bovino, podendo infectar também outras espécies, como búfalos, camelos, cervídeos, cães, equinos, ovinos e o homem (Stack \& Macmilian, 2007; Silva, 2015). Em fêmeas, o aborto geralmente ocorre a partir do sexto mês de gestação (Antoniassi et al, 2007). A infecção por $B$. abortus em bovinos ocorre principalmente pela ingestão de alimentos e água contaminados com produtos de aborto, como fetos, descargas uterinas e restos placentários (Silva, 2015).

Em vacas confirmadas para brucelose, ou chamadas brucélicas a primeira e a segunda gestação geralmente terminam em aborto. Sendo eliminadas as bactérias junto à placenta, contaminando os pastos e consequentemente, os animais do rebanho (Silva, 2015). Nas gestações seguintes, normalmente não ocorrem grandes problemas. Porém, apesar de não apresentar sinais clínicos, vacas contaminadas continuam eliminando bactérias e contaminando o ambiente (Castro \& Gabriel, 2009; Silva, 2015).

Dentre os sinais clínicos mais comuns estão o nascimento de bezerros fracos ou natimortos, retenção de placenta e queda na produção de leite (Santos \& Vasconcelos, 2009).

Também é relatada na forma crônica. Forma essa que mais acomete animais na fase adulta, causando prejuízos na forma de infertilidade e abortamentos no terço final de gestação (Faine, 1999; Grooms \& Bolin, 2007).

A Rinotraqueíte é uma doença infecciosa que acomete bovinos nas mais variadas fases de vida do animal, pertencente à família Herpesviridae (Thiry et al., 2007), dividida em três subfamílias: Alpha, Beta e Gammaherpesvirinae (Thiry et al., 2007; Roizmann \& Pellett, 2007). A principal fonte de contaminação do BoHV-1 no organismo dos bovinos são: via mucosa oro-nasal, genital e ocular (Aono, 2012). Podendo ocorrer na forma direta, através do contato e por aerossóis e secreções de animais em estágio sintomático (Mars et al., 2000; Aono, 2012).

Além das falhas no que diz respeito a reprodução, a Rinotraqueíte provoca a diminuição da produção de leite por ser de caráter infeccioso e diminuir a qualidade do sêmen dos machos (Franco \& Roehe, 2007).

A BVDV (Diarreia viral bovina) é uma doença infecciosa de caráter mundial que tem grandes impactos na economia por causar a morte de animais jovens e a perda de peso de animais adultos (Aono, 2012). É a virose de maior importância depois da febre aftosa (Baker, 1995). Dados mostram taxas de aborto de $35 \%$ para as novilhas prenhas e $23 \%$ para vacas em gestação em rebanhos com problemas em relação a essa virose (Pence, 2011). No Brasil, a taxa de aborto atinge os $41 \%$ de vacas gestantes (Arenhart et al., 2008).

Recomenda-se a vacinação em locais onde a infecção por herpesvírus é endêmica e também em propriedades onde haja condições favoráveis para a transmissão viral. Portanto, a imunização dos animais torna-se uma maneira eficaz de diminuir as perdas econômicas advindas da manifestação clínica da doença (Patel, 2005; Silva, 2015).

O Neospora Caninum é um protozoário coccídeo, que infecta várias espécies animais, dentre elas canídeos domésticos e selvagens, bovinos, equídeos (Adreotti et al., 2010) e pequenos ruminantes, como os caprinos (Dubey, 2003; Varaschin et al., 2012; Mesquita et al., 2013).

A neosporose possui grande capacidade de transmissão dentro do rebanho, chegando a infectar $90 \%$ dos animais (Dubey et al., 2003). A transmissão pode ocorrer de mãe para filho, pela ingestão de oocistos (Dubey et al., 2003) e a transmissão transplacentária, ocorrendo de forma repetida no mesmo animal e durante muitas gerações através da progênie (Anderson et al., 2000; Silva, 2015). 
Outras formas de transmissão são infecção pós-natal ou através da ingestão de oocistos liberados pelos cães (Davison et al., 2001). Estes também podem se infectar pela ingestão de leite ou colostro infectados (Hall et al., 2005).

Alguns autores relatam também como causa de aborto, os considerados acidentes físicos ou abortos traumáticos, devido a contusões decorrentes da movimentação muito rápida dos animais em ambientes diversos, pisos molhados, escorregadios e irregulares, projeções pontiagudas nas instalações, densidades baixas ou elevadas durante o transporte, estresse crônico comuns em raças de "sangue quente" como os zebuínos, manejos com superlotamento (Civeira et al., 2006), chifradas, coices, pisoteio e tombos (Braggion \& Silva, 2004).

\section{Distocia}

A distocia ou parto distócico é uma complicação no parto ou dificuldade de realizar o mesmo de maneira normal e natural, sendo necessária intervenção para que a cria venha a nascer, de maneira rápida e segura, sem comprometer a vaca e o bezerro (Borges et al., 2006).

Dentre os distúrbios referentes à distocia que mais acontecem durante a gestação, parto e puerpério estão a retenção de placenta, gestação múltipla, gestação prolongada, infecção e prolapso uterino (Camargos, 2013).

A distocia é um importante problema da pecuária leiteira, pois está associada ao aumento na susceptibilidade a doenças e a mortalidade de bezerros, causando aumento dos custos com veterinários e medicamentos, além da demora no retorno ao cio e menor grau de concepção e, em alguns casos, até a morte do animal (Camargos, 2013).

Podendo ser de origem materna ou fetal, ou ainda, o fato do feto ser grande em relação a estrutura da fêmea, devido a raça, vacas pequenas gestando bezerros de touros de grande porte, impossibilitando de maneira natural que o bezerro consiga passar pela pélvis da vaca (Borges et al., 2006).

A ocorrência de distocia muitas vezes está relacionada com o tamanho do feto (Borges et al., 2006), mas também pode ocorrer devido a condição corporal da fêmea gestante no momento do parto. Vários fatores de risco como deficiências nutricionais, fatores ambientais, fisiológicos e genéticos podem provocar aumento na incidência de retenção de placenta e distocia (Santos et al., 2002).

Segundo Grohn e Rajala-Shultz (2000) e Ettema e Santos (2004), a distocia está relacionada muitas vezes às vacas primíparas e ao sexo do bezerro, pois os machos são em tamanho maiores que as fêmeas, aumentando o esforço da fêmea.

\section{Gestação Gemelar}

As sequelas deixadas pela gemelaridade incluem período de gestação encurtado, pois os bezerros acabam nascendo antes dos nove meses, podendo haver, abortamento, natimortos, distocia, e ou, retenção de placenta. A gestação gemelar pode estar associada a diminuição da fertilidade, ao aumento da mortalidade neonatal, a bezerros com menores pesos e a maior intervalo de parto, resultando em perdas econômicas significativas (Hafez, 2003).

Vacas que passaram por gestações gemelares enfrentam grandes desafios após o parto, evidenciados pela elevada incidência de doenças ou distúrbios que interferem em sua capacidade de produção leiteira (Lopes, 2013). Os bezerros gêmeos tendem a apresentar desenvolvimento inferior, tamanho menor, puberdade mais tardia, o que compromete a reposição de animais no rebanho (Lopes, 2013).

É muito variável a ocorrência de parto gemelar em bovinos. Porém em condições naturais, estima-se que ocorre em torno de 3 a 5\% dos partos (Silva, 2015). Dos casos relatados, cerca de 10 \% são embriões que se dividiram originando gêmeos idênticos e 95 \% são provenientes de ovulação múltipla, que é a forma mais comum (Santos \& Vasconcelos, 2007; Mathias, 2014). 
Os bovinos são uma espécie monotócica, o que significa na maioria das vezes, o nascimento de um único filhote. Nem sempre nasce apenas um filhote, casos considerados raros acontecem. Um exemplo são os chamados "gêmeos". Fato esse que é determinado quando em uma onda folicular, em vez de um, dois folículos são considerados dominantes. Essa situação é chamada de co-dominância e passam a ser fecundados durante a ovulação resultando em dois embriões, gerando futuramente o nascimento de gêmeos (Lopes, 2013).

Os gêmeos podem ser divididos em dois tipos (Fricke \& Shaver, 2001). Os monozigóticos são considerados gêmeos verdadeiros, que são idênticos tanto fenotipicamente como geneticamente e os dizigóticos que podem ser do mesmo sexo ou do sexo oposto. Não são idênticos geneticamente, apenas parecidos (Morris \& Day, 1986; Van Vleck et al., 1991; Lopes, 2013).

Os fatores que podem estar envolvidos na ocorrência de gemelaridade em vacas leiteiras são: a raça, número de partos, sazonalidade, seleção genética, a taxa de ovulação, produção leiteira, utilização de substâncias exógenas como a somatotropina bovina recombinante (rbST) e a alimentação (Lopes, 2013).

Lopes (2013) afirma que a duração da gestação gemelar dura em torno de 5 a 10 dias a menos que uma gestação normal. Isto aumenta a ocorrência de retenção de placenta, com risco de distocia, que ainda reduzem as taxas de concepção em 7 a 8\% (Echternkamp \& Gregory, 2002).

$\mathrm{Na}$ gestação gemelar, os prejuízos mais comuns envolvem os gêmeos do sexo oposto. Nesse caso a fêmea é estéril, devido ao distúrbio freemartin que acontece quando há fusão da membrana placentária dos fetos. Nesse processo, fatores endócrinos e celulares advindos do feto macho causam um desenvolvimento anormal dos órgãos reprodutivos do feto fêmea (Dias, 2000; Pensani \& Beltran, 2009). A fêmea não se reproduz e possui aparência muscular de um macho.

Freemartin é uma má formação genital observada em gestações gemelares, com $90 \%$ da ocorrência de gêmeos de sexos opostos, ou seja, macho e fêmea (Pensani \& Beltran, 2009).

Os ovários de uma fêmea nessas condições não possuem um desenvolvimento correto, pela ineficiência na produção de hormônios necessários para induzir o sinal de cio. Além de comprometer o desenvolvimento dos órgãos externos, resultando em uma vulva pequena e os tetos atrofiados (Jackson, 2004).

Estudos demostram que, de cada 200 nascimentos de gêmeos, um é de gêmeos de sexos opostos. Lembrando que a infertilidade só ocorre se os sexos forem diferentes. Quando são gêmeos de duas fêmeas ou de dois machos não haverá problemas de fertilidade (Pensani \& Beltran, 2009).

\section{Natimorto}

Natimorto é definido como o bezerro completamente formado com morte antes, durante ou $48 \mathrm{~h}$ após o parto (Meyer et al., 2001). Em novilhas de primeira cria, tem ocorrência de $11 \%$ e, em vacas multíparas, de $5,7 \%$, sendo que metade dos natimortos ocorre devido a partos distócicos e a outra metade devido aos partos não assistidos.

Os manejos intensivos que os modelos produtivos abrigam os animais de alta aptidão leiteira favorecem a transmissão de várias enfermidades de caráter infeccioso (Médici et al., 2000). Sendo as causas responsáveis pelo histórico de natimortalidade em um rebanho relacionadas principalmente a doenças infecciosas (Campos, 2009; Paula et al., 2015).

As doenças que mais influenciam a natimortalidade são a brucelose, leptospirose, rinotraqueíte infecciosa bovina (IBR) e diarreia viral bovina (BVD) (Silva, et al., 2015).

Afetando diretamente o bolso de produtor devido a redução do índice de nascimentos, ao descarte prematuro dos animais, a infertilidade, a queda na produção leiteira, entre outros prejuízos. 
Santana (2013) relata que os abortamentos e natimortos representam grande redução da produção leiteira da vaca durante toda sua vida produtiva e acarreta grandes prejuízos econômicos.

\section{CONSIDERAÇÕES FINAIS}

Animais selecionados para produção leiteira estão mais susceptíveis às infecções, devido à seleção artificial. O manejo intensivo pode contribuir para o aumento nas taxas de aborto e natimortos nas granjas leiteiras. Maternidade na propriedade pode contribuir para a diminuição de ocorrências das enfermidades, através da individualização dos animais e um melhor controle zootécnico. Conhecer as falhas reprodutivas e suas respectivas causas auxilia no controle e na eliminação de focos infecciosos que diminuem a lucratividade da propriedade.

\section{REFERÊNCIAS}

ADREOTTY, R.; BARROS, J.C.; PEREIRA, A.R. Association between seropositivy for Neospora caninum and reproductive performance of beef heifers in the Pantanal of Mato Grosso do Sul, Brazil. Revista Brasileira Parasitologia Veterinária. v.19, p.119-123, 2010. https://doi.org/10.4322/rbpv.01902010

ALVAREZ, R.F. Dez perguntas e respostas sobre anestro pós-parto em bovinos leiteiros. Pesquisa e Tecnologia, 2013. Disponível em:<www.aptaregional.sp.gov.br>. Acesso em 18 out. 2016.

ALVES, N.G. Atividade ovariana em fêmeas bovinas da raça holandesa e mestiças holandês x zebu, durante dois ciclos estrais normais consecutivos. Revista Brasileira de Zootecnia, v.31, n.2, p.634634, 2002. https://doi.org/10.1590/S1516-35982002000300012

ANDERSON, M.L.; ADRIANARIVO, A.G.; CONRAD, P.A. Neosporosis in catle. Animal Reproduction Sience. v.60-61, p.417-431, 2000. https://doi.org/10.1016/S0378-4320(00)00117-2

ANTONIASSI, N.A. B; SANTOS, A.S; OLIVEIRA, E.C. Diagnostico de causas infecciosas de aborto em bovinos. Biológico. v.69, n.2, p.69-72, 2007;

AONO, F.H.S.; VASCONCELOS, J.L.M. Incidência de perdas gestacionais e efeito da vacinação contra doenças da reprodução nas taxas de prenhez em vacas de corte submetidas à inseminação artificial em tempo fixo. 2012. 19f. Tese de dissertação (em Zootecnia). UNESP - BOTUCATU - SP.

ARENHART, S.; SILVA, L.F.; HENZEL, A. Proteção fetal contra o vírus da diarréia viral bovina (BVDV) em vacas prenhes previamente imunizadas com uma vacina experimental atenuada. Pesquisa Veterinária Brasileira, v.28, p.461-470, 2008. https://doi.org/10.1590/S0100-736X2008001000004

ATANASOV, A.S.; DINEVA, J.D.; YOTOV, S.A. Ultrasonic evaluation of uterine involution in Bulgarian Murrah buffalo after administration of oxytocin. Animal Reproduction Science, v.133, p.71-76, 2012. https://doi.org/10.1016/i.anireprosci.2012.06.002

BAGNATO, A.; OLTENACU, P.A. Phenotypic evaluation of fertility traits and their association with milk production of Italian Friesian cattle. Journal of Dairy Science, v.77, p.874-882, 1994. https://doi.org/10.3168/ids.S0022-0302(94)77022-3 
BAKER, J.C. The clinical manifestations of bovine viral diarrhea infection. The Veterinary Clinics of North America: Food Animal Practice, Philadelphia, v.11, p.425-445, 1995. https://doi.org/10.1016/S0749-0720(15)30460-6

BARBOSA, C.F.; JACOMINI, J.O.; GOMES, E. Inseminação artificial em tempo fixo e diagnóstico precoce de gestação em vacas leiteiras mestiças. Revista Brasileira de Zootecnia, v.40, n.1, p.7984, 2011. https://doi.org/10.1590/S1516-35982011000100011

BARUSELLI, P.S.; REIS, E.L.; MARQUES, M.O. The use of hormonal treatments to improve reproductive performance of anestrous beef cattle in tropical climates. Animal Reproduction Science, 82-83:479-486, 2004. https://doi.org/10.1016/i.anireprosci.2004.04.025

BELLOWS, R.A.; SHORT, R.E.; RICHARDSON, G.V. Effects of sire, age of dam and gestation feed level on dystocia and postpartum reproduction. Journal of Animal Science, 55:1827, 1982. https://doi.org/10.2527/jas1982.55118x

BERGAMASCHI, M.A.C.M.; MACHADO, R.; BARBOSA, R.T. Eficiência reprodutiva das vacas leiteiras. Circular Técnica Embrapa, v. 64, p. 1-12, 2010.

BORGES, M.C.B.; COSTA, J.N.; FERREIRA, M.M. Caracterização das distocias atendidas no período de 1985 a 2003 na Clínica de Bovinos da Escola de Medicina Veterinária da Universidade Federal da Bahia. Revista Brasileira de Saúde Produção Animal, v.7, n.2, p.87-93, 2006.

BUTLER, W.R. Nutritional interactions with reproductive performance in dairy cattle. Animal Reproduction Science, v.60, p.449-457, 2000. https://doi.org/10.1016/S0378-4320(00)00076-2

BUTLER, W.R. Energy balance relationships with follicular development, ovulation and fertility in postpartum dairy cows. Livestock Production Science, v.83, p.21-218, 2003. https://doi.org/10.1016/S0301-6226(03)00112-X

BURNS, B.M.; FORDYCE G.; HOLROYD R.G. A rewiew of factors that impact on the capacity of beef cattle females to conceive, maintain a pregnancy and wean a calf - Implications for reproductive efficiency in northern Australia. Animal Reproduction Science. In press, 2010. https://doi.org/10.1016/i.anireprosci.2010.04.010

BRAGGION, M.; SILVA, R.A. Quantificação de Lesões em Carcaças de Bovinos Abatidos em Frigoríficos no Pantanal Sul-Mato-Grossense. Corumbá, Comunicado técnico 45 Embrapa Pantanal, 2004.

CAMARGOS, A.S. Ocorrência de falhas reprodutivas em fêmeas leiteiras no município de Coronel Xavier Chaves - MG. 2009. 36f. Monografia - Especialização: Departamento de Medicina Veterinária, Universidade Federal de Lavras, Lavras.

CAMARGOS, A.S.; GIOSO, M.M.; REIS, L.S.L.S et al. Ocorrência de distúrbios da gestação, parto e puerpério em vacas leiteiras. Revista Científica Eletrônica de Medicina Veterinária - ISSN: 16797353, Ano XI, v. 20, Janeiro de 2013.

CAMPOS, C. Aborto: indique as causas para evitar perdas. Revista Balde Branco, v.4, p.21-25, 2009. Disponível:<http://www.biologico.sp.gov.br/noticias.php>Acesso em: 24/09/2016. 
CARNEIRO, M.A.; BERGAMASCHI, M. Eficiência reprodutiva das vacas leiteiras. Circular Técnica 64. ISSN 1981-2086, São Carlos - SP, p.4-12, 2010.

CASTRO, K.N.C.; GABRIEL, A.M.A. Porque preocupar-se com a brucelose bovina? 2009. Disponível: http://www.infobibos.com/Artigos/2009_1/Brucelose/index. Acesso em: 24/09/2016.

CIVEIRA, M.P.; RENNER, R.M.; VARGAS, R.E.S. Avaliação do bem-estar animal em bovinos abatidos para consumo em frigorífico do Rio Grande do Sul. Veterinária em Foco, Canoas, v.4, n.1, p.5-11, 2006.

CORTEZ, A. CASTRO, A.M.G.; HEINEMANN, M.B. Deteç̧ão de ácidos nucléicos de Brucella spp., Leptospira spp., herpesvirus bovino e vírus da diarréia viral bovina, em fetos abortados e em animais mortos no perinatal. Arquivo Brasileiro de Medicina Veterinária e Zootecnia, v.58, p.1228, 2006. https://doi.org/10.1590/S0102-09352006000600036

DAVISON, H.C.; GUY, C.S.; MCGARRY, J.W. Experimental studies on the transmission of Neospora caninum between cattle. Research in Veterinary Science, v. 70, p. 163-168, 2001. https://doi.org/10.1053/rvsc.2001.0457

DIAS, R.O.S. O alto custo dos partos gemelares. 2000. Disponível em: <http://www.milkpoint.com.br/radar-tecnico/medicina-da-producao/o-alto-custo-dos-partosgemelares-16638n.aspx> Acesso em:23/09/2016.

DUBEY, J.P. Review of Neospora caninum and neosporosis in animals Korean J. Parasitol. v.41, p.116, 2003. https://doi.org/10.3347/kjp.2003.41.1.1

ECHTERNKAMP, S.E.; FERRELL, C.D.; RONE, J.D. Influence of pre-and postpartum nutrition on LH secretion in suckled postpartum beef heifers. Theriogenology, v.18, p. 283-295, 1982. https://doi.org/10.1016/0093-691X(82)90006-1

ECHTERNKAMP S.E.; GREGORY K.E. Reproductive, growth, feedlot, and carcass traits of twin vs single births in cattle. Journal of Animal Science, v.80, p.64-73, 2002. https://doi.org/10.2527/animalsci2002.80E-Suppl 21b

ETTEMA, J.F.; SANTOS, J.E.P. Impact of age calving on lactation, reproduction, health, and income in first-parity Holsteins on commercial farms. Journal of Dairy Science, v.87, p.2730-2742, 2004. https://doi.org/10.3168/ids.S0022-0302(04)73400-1

FAINE, S. Leptospira and leptospirosis. CRC Pres Melbourne: Medicine Science, p.353, 1994. https://doi.org/10.1016/i.vetmic.2009.03.012

FAINE, S. Leptospira and Leptospirosis. 2a ed. Medicine Science, Melbourne. p.353, 1999.

FRANCO, A.C.; ROEHE, P.M. Hespesviridae. in Flores, Virologia Veterinária, Santa Maria-RS, Ed. Da UFSM, cap.17, p.433-488, 2007.

FRICKE P.M.; SHAVER R.D. Managing reproductive disorders in dairy cows. Dairy up-dates. Reproduction and Genetics, p.603, 2001 
GIVENS, M. D. A clinical, evidence-based approach to infectious causes of infertility in beef cattle. Theriogenology, v.66, p.648-654, 2006. https://doi.org/10.1016/i.theriogenology.2006.04.021

GROHN, Y.T.; RAJALA-SCHULTZ, P.J. Epidemioly of reproductive performance in dairy cows. Animal Reproduction Science, v.60-61, p.605-614, 2000. https://doi.org/10.1016/S0378-4320(00)00085-3

GROOMS, D.L.; BOLIN, S.R.; COE P.H.Fetal protection against continual exposure to bovine viral diarrhea virus following administration of a vaccine containing an inactivated bovine viral diarrhea virus fraction to cattle. Amimal Journal Veterinária Revista. 2007; v.68, p.1417-22. https://doi.org/10.2460/ajvr.68.12.1417

GROOMS D.L. Programs to control ifectious diseases and improve reproductive performance. Curso: Novos Enfoques da Produção e Reprodução de Bovinos [CDROM], 2010.

HAFEZ, E.S.E. Reprodução Animal. 7ạ ed. São Paulo: Manole, 2003. 582 p.

HALL, C.A.; REICHEL, M.P.; ELLIS, J.T. Neospora abortions in dairy cattle: diagnosis, mode of transmission and control. Veterinary Parasitology, v.128, p.231-241, 2005. https://doi.org/10.1016/i.vetpar.2004.12.012

HANSEN, P.J.; ARECHIGA, C.F. Strategies for managing reproduction in heat-stressed dairy cow. Journal of Animal Science, v.77, suppl. 2, p.36-50, 1999. https://doi.org/10.2527/1997.77suppl 236x

JACKSON, P.; COCKCROFT. P. Exame Clínico dos Animais de Fazenda. Editora Andrei, p.188-206, 2004.

JUFFO, G.D. Aborto em bovinos principais causas infecciosas. 2010. $16 f$ Monografia. UFRGS. PORTO ALEGRE - RS.

KHODAKARAM-TAFTI, A.; IKEDE, B.O. A retrospective study of sporadic bovine abortions, stillbirths, and neonatal abnormalities in Atlantic Canada, from 1990 to 2001. Canadian Veterinary Journal. v.46, p.635-637, 2005.

KELLING, C.L. Viral Diseases of the Fetus. Virology, Nebraska Center for Virology Papers. Virology papers. Pag. 399-408, 2007. https://doi.org/10.1016/B978-072169323-1.50053-2

LALMAN, D.L.; KEISLER D.H.; WILLIAMS, J.E. Influence of postpartum weight and body condition change on duration of anestrus by undernourished suckled beef heifers. Journal of Animal Science, v.75, p.2003-2008, 1997. https://doi.org/10.2527/1997.7582003x

LAMB, G.C.; LYNCH J.M.; GRIEGER D.M. Ad libitum suckling by an unrelated calf in the presence or absence of a cow's own calf prolongs postpartum anovulation. Journal of Animal Science, v.75, p.2762-2769, 1997. https://doi.org/10.2527/1997.75102762x

LOPEZ-GATIUS, F.; LOPEZ BEJAR, M.; FENECH, M. Ovulation failure and double ovulation in dairy cattle: risks factors and effects. Theriogenology, v.63, p.1298-1307,2005. https://doi.org/10.1016/i.theriogenology.2004.06.010 
LOPES, J. Gemelaridade em vacas leiteiras: incidência e a sua influência no desempenho produtivo em explorações do Litoral Norte de Portugal. 2013. 13- 28 f. Dissertação (Mestrado em Medicina veterinária) - Universidade de Trás-os-Montes e Alto Douro, Vila Real.

MARS, M.H.; JONG, M.C.; VAN OIRSCHOT J.T. AgE-negative bovine herpesvirus 1 vaccine strain is not re-excreted nor transmitted in an experimental cattle population after corticosteroid treatments. Vaccine. v.18, p.1975-1981, 2000. https://doi.org/10.1016/S0264-410X(99)00536-8

MATHIAS, J. Bezerros gêmeos. $2014 . \quad$ Disponível em :http://revistagloborural.globo.com/vidanafazenda/grresponde/noticia/2014/01/bezerrosgemeos.html> Acesso em: 23/09/2016.

MCEWAN, B.; CARMAN, S. Animal health laboratory reports--cattle. Bovine abortion update, 19982004. Canadian Veterinary Journal. 46:46 2005.

MÉDICl, K.C.; ALFIERI, A.A.; ALFIERI, A.F. Prevalência de anticorpos neutralizantes contra o herpesvírus bovino tipo 1 , decorrente de infecção natural, em rebanhos com distúrbios reprodutivos. Ciência Rural, v.30, n.2, p.347-350, 2000. https://doi.org/10.1590/S010384782000000200025

MESQUITA, L.P.; NOGUEIRA, C.I.; COSTA, R.C. Antibody kinetics in goats and conceptuses naturally infected with Neospora caninum. Veterinaria Parasitol. v.196, p.327-332, 2013. https://doi.org/10.1016/i.vetpar.2013.03.002

MEYER, C.L.; BERGER, P.J.; KOEHLER, K..J. Phenotypic trends in incidence of stillbirth for Holsteins in the United States. Jounal Dairy Science. v.84, p.515-523, 2001.

https://doi.org/10.3168/ids.S0022-0302(01)74502-X

MINEIRO, A.L.B.B.; Bezerra, E.E.A.; Vasconcellos, S.A. Infecção por leptospira em bovinos e sua associação com transtornos reprodutivos e condições climáticas. Arquivo Brasileiro de Medicina Veterinária e Zootecnia; v.59, p.1103-1109, 2007. https://doi.org/10.1590/S0102$\underline{09352007000500003}$

MIZUTA, K. Estudo comparativo dos aspectos comportamentais do estro e dos teores plasmáticos de $\mathrm{LH}, \mathrm{FSH}$, progesterona e estradiol que precedem a ovulação em fêmeas bovinas Nelore (Bos taurus indicus), Angus (Bos taurus taurus) e Nelore $x$ Angus (bos taurus indicus $\times$ bos taurus taurus). São Paulo, 2003. 98f. Tese (Doutorado) - Faculdade de Medicina Veterinária e Zootecnia, Universidade de São Paulo, São Paulo, 2003.

MONTEIRO, J. Leptospirose $\quad$ Bovina. $2011 . \quad$ Disponível em:<http://www.agrolink.com.br/saudeanimal/artigo/leptospirosebovina_126483.hml> Acesso em: 20/09/2016.

MONTIEL, F.; AHUJA, C. Body condition and suckling as factors influencing the duration of postpartum anestrus in cattle: a review. Animal Reproduction Science, v.85, p.1-26, 2005. https://doi.org/10.1016/j.anireprosci.2003.11.001

MORRIS C.A.; DAY, A.M. Ovulation results from cattle herds with high twinning fre-quency. Proceedings of the 3rd World Congress on Genetics Applied to Livestock Production, p.96-100, 1986. 
OLIVEIRA, R. L.; BARBOSA, M.A.A.F.; LADEIRA, M.M Nutrição e manejo de bovinos de corte na fase de cria. Revista Brasileira de Saúde e Produção Animal, v.7, p.57-86, 2006.

PAULA, F.H.; CAMARGOS, A. S.; SILVA, V. L. Ocorrência de natimorto em vacas leiteiras de alta produção do Município de Morrinhos - GO. Resumo expandido. In: IV Congresso Estadual de Iniciação Científica do IF Goiano, 2., 2015, Morrinhos. Anais... Congresso Estadual de Iniciação Científica do IF Goiano 2015, p.1-1.

PANSANI, M.A.; BELTRAN M.P. Freemartin. Revista Científica Eletrônica de Medicina Veterinária ISSN: 1679-7353. Ano VII - Número 12 - Janeiro de 2009 - Periódicos Semestral, FAMED. Pág. 3.

PATEL, J.R. Characteristics of live bovine herpesvirus-1 vaccines. Veterinaria Journal, v.169, p.404416, 2005. https://doi.org/10.1016/i.tvjl.2004.03.005

PENCE, M. Bovine Virus Diarrhea (BVD), BVD PI and the new vaccines. Disponível em: http://ads.caes.uga.edu/extension/beefteam/pdf/MBVDPInewvaccinepdf. Acesso em: 20/09/2016.

PETER, A.T.; LEVINE, H.; DROST, M. Compilation of classical and contemporary terminology used to describle morphological aspectas of ovarian dynamics in cattle. Theriogenology, v.71, p.13431357, 2009. https://doi.org/10.1016/j.theriogenology.2008.12.026

PEREIRA, M.R.C. Estratégias de vacinação contra doenças da reprodução nas taxas de prenhez de vacas em lactação. 2012. Dissertação (Mestrado em Zootecnia), USP- Universidade Estadual de São Paulo - Campus de Botucatu.

PINHEIRO, V.G.; CURY, J.R.L.M.; SATRAPA, R.A. Evaluation of the hypothalamus-pituitary axis response to exogenous $\mathrm{GnRH}$, estradiol benzoate, and LH during the postpartum period in Nellore cows. Theriogenology, v.79, p.797-802, 2013. https://doi.org/10.1016/i.theriogenology.2012.12.006

RABASSA, V.R; PFEIFER, L.F.M.; SCHNEIDER, A. Anestro pós-parto em bovinos: mecanismos fisiológicos e alternativas hormonais visando reduzir este período -uma revisão. Revista da FZVA, Uruguaiana, v.14, n.1, p.139-161, 2007.

RIET-CORREA, F.; SCHILD, A.L.; LEMOS, R.A.A. Doenças de Ruminantes e Equinos. 3. ed. Santa Maria: Fernovi Editora, 2007.

ROIZMANN, B.; PELLETT, P.E. The Family herpesviridae: a brief introduction, in: Knipe, M. D. \& Howley, P. M., Field`s Virology, Philadelphia-USA, 5th Ed. Lippincott Williams \& Wilkins, v.2, p.2480-2497, 2007.

RUAS J.R.M.; MARCATTI NETO A.; AMARAL, R. Programa de bovinos da EPAMIG - pesquisa com animais F1: projetos e resultados preliminares. In: ENCONTRO DE PRODUTORES DE GADO LEITEIRO F1, 4., 2002. Belo Horizonte. Anais... Belo Horizonte: UFMG, EV, p.60-68, 2002.

SANTANA, S; MASSA, M; ZAFALON, Z. Estudo epidemiológico sobre as perdas reprodutivas em bovinos leiteiros: ocorrência de neospora caninum, brucella abortus, herpesvírus bovino tipo-1 e 
leptospira spp. em uma propriedade do município de São Carlos-SP. ARS veterinaria, v.29, n.3, p.153-160, 2013.

SANTOS, R.M.; VASCONCELOS, J.L.M.; SOUZA, A.H. Efeito da aplicação de prostaglandina (PGF2a ) no pós-parto imediato sobre a incidência de retenção de placenta em vacas de leite. Arq. Bras. Med. Vet. Zootec., v.54, n.1, p.110-115, 2002. https://doi.org/10.1590/S0102$\underline{09352002000100005}$

SANTOS, R.M.; VASCONCELOS, J.L.M. O que é uma novilha maninha? 2007. Disponível em: <http://www.milkpoint.com.br/radar-tecnico/reproducao/o-que-e-uma-novilha-maninha41586n.aspx> Acesso em: 25/09/2016.

SANTOS, R.M.; VASCONCELOS, J.L.M. Abortamento em vacas leiteiras. Disponível em: <http://www.milkpoint.com.br/radartecnico/reproducao/abortamento-em-vacas leiteiras 50822n.aspx>, MilkPoint, 2009.

SILVA, F.J.; CONCEIÇÃO, L.F.; FAGLIARI, J.J. Prevalencia e fatores de risco de leptospirose bovina no estado do Maranhão. Pesquisa Veterinária Brasileira. v.32, n.2, p.303-312, 2012. https://doi.org/10.1590/S0100-736X2012000400006

SILVA, L.R; FRANCO, R.F; DIANA, T.F. Ocorrência de falhas reprodutivas em rebanho leiteiro de alta produção: estudo retrospectivo. In: XXIV Congresso Brasileiro de Zootecnia. Anais... Vitória, Zootec, 2014.

SILVA L.R. Ocorrência de falhas reprodutivas em rebanho leiteiro de alta produção: estudo retrospectivo. 2015. 55 f. Monografia (Zootecnia). Universidade Federal de São João Del Rei. São João Del Rei - MG. 2015.

STACK, J, A; MACMILLAN, A, P. Identification and Biotyping of Brucella spp Brunet Publication, 2007. Disponível em: <http//progress.box.co.il/bremetul> Acesso em: 20/09/2016.

THATCHER, W.W.; BILBY, T.R.; BARTOLOME, J.A. Strategies for improving fertility in the modern dairy cow. Theriogenology. v.65, p.30-34, 2006. https://doi.org/10.1016/i.theriogenology.2005.10.004

THIRY, J.; WIDÉN, F.; GRÉGOIRE, F. Isolation and characterisation of ruminant alphaherpesvirus closely related to bovine herpesvirus 1 in a free ranging red deer. BioMed Central Veterinary Research, v.3, p.26, 2007. https://doi.org/10.1186/1746-6148-3-26

VAN VLECK, L.D.; GREGORY, K.E.; ECHTERNKAMP, S. E. Ovulation rate and twinning rate in cattle: Heritabilities and genetic correlation. Journal of Animal Science, 1991. https://doi.org/10.2527/1991.6983213x

VARASCHIN, M.S.; HIRSCH, C.; WOUTERS, F. Congenital Neosporosis in Goats from the State of Minas Gerais, Brazil.Korean J. Parasitol. v. 50, p. 63-67, 2012. https://doi.org/10.3347/kjp.2012.50.1.63

YAVAS, Y.; WALTON J.S. Postpartum acyclicity in suckled beef cows: a review. Theriogenology, v.54, p.25-55, 2000. https://doi.org/10.1016/S0093-691X(00)00323-X 